\title{
A Method for the Differentiation of Frozen-thawed from Unfrozen Fish Fillets by a Combination of Torrymeter Readings and $\mathrm{K}$ Values
}

\author{
Jong-Bae Kim,*1 Michiyo Murata,*2 and Morihiko Sakaguchi*2 \\ (Accepted June 6, 1986)
}

\begin{abstract}
A method to differentiate between frozen-thawed and unfrozen fillets of yellowtail Seriola quinqueradiata was investigated by a combination of Torrymether readings (TMR) and $\mathrm{K}$ values (KV). Fresh fillets before storage and fillets held in ice for about a day showed an average TMR of approximately 11. KV for corresponding fillets were less than 1 and about $6 \%$, respectively. TMR for frozen fillets stored at $-20^{\circ} \mathrm{C}$ for about a day prior to thaw and unfrozen fillets held in ice for 18 days were both 0 . The frozen-thawed fillets had relatively low $\mathrm{KV}$, while the unfrozen ones had a considerably high level (approximately 3 vs. $50 \%$ ), suggesting that the former fillets can be differentiated from the latter by measuring the TMR and KV. Thawed fillets previously frozen only in liquid nitrogen and those frozen by this and subsequently stored at $-20^{\circ} \mathrm{C}$ for about a day also showed a TMR of 0. TMR of frozen-thawed fillets measured on the bone as well as on the skin side were much lower than those of the unfrozen fillets. A possibility to differentiate frozen $\left(-20^{\circ} \mathrm{C}\right.$ for a day)-thawed from unfrozen fillets by a combination of visual observation of the skin color and the TMR or KV measurement was also indicated.
\end{abstract}

There have been many reports on methods for the differentiation of frozen-thawed fish from the unfrozen." Recently, the following were proposed: the determination of hematocrit values ${ }^{2,3}$ and some lysosomal and mitochondrial enzyme levels, ${ }^{4-\theta)}$ and the examination of medulla of crystalline lens. ${ }^{\text {?) }}$ Some of these methods, however, include procedures considerably complicated or are limited to intact fish which contain red blood cells and thus can not be applied to fillets.

The $\mathrm{K}$ value (the proportion of hypoxanthine and inosine in the total amount of ATP and its degradation products) is widely known as a freshness index..$^{8)}$ The effectiveness of the Torrymeter to assess the freshness of fish (intact fish and fillets) has been suggested, ${ }^{, 1},{ }^{102}$ since the readings of this meter decrease when freshness decreases. The Torrymeter is reported to give extremely low readings for fish once frozen even though they are highly fresh. The possibility of using this effect together with sensory methods to differentiate frozen-thawed from unfrozen fillets has been suggested. ${ }^{2)}$ The sensory methods, however, are primarily based on subjective procedures; the results obtained often vary among panelists. In this work, we propose a method for the differentia- tion of frozen-thawed from unfrozen yellowtail fillets, which uses the Torrymeter readings in combination with $\mathrm{K}$ values rather than sensory methods. In aid of the differentiation, changes in color of the skin and muscle of the fillets was examined before and after the freeze and thaw.

\section{Materials and Methods}

\section{Materials}

Live yellowtail Seriola quinqueradiata, weighing $1.0-1.4 \mathrm{~kg}$ each, were purchased from a local market. They were decapitated and filleted immediately. The fillets were rinsed lightly with ice-cold $1.5 \%$ sodium chloride solution and drained briefiy. One of the two fillets obtained from each fish was collected and 2 to 12 fillets were used for each storage experiment.

For ice storage, the fillets were individually pakaged in polyethylene bags $(30 \times 45 \mathrm{~cm})$. The bags were sealed to prevent contamination from melted ice and submerged in ice which was replaced every day during storage. For freeze storage, the fillets were placed in a freezer at $-20^{\circ} \mathrm{C}$ for $18 \mathrm{~h}$ or dipped in liquid nitrogen for $30-40 \mathrm{~min}$. Another batch of fillets was stored in the freezer

*1 Kunsan Junior Fisheries Technology College, Kunsan, Korea (金 蟑培：群山水座専門大学).

*2 The Research Institute for Food Science, Kyoto University, Uji, Kyoto 611, Japan (村田道代, 坂口守彦: 京都大学食粅科学研究所). 
at $-20^{\circ} \mathrm{C}$ for $18 \mathrm{~h}$ immediately after being frozen in liquid nitrogen for $30-40 \mathrm{~min}$. To thaw the fillets, each one was double packaged in polyethylene bags $(30 \times 45 \mathrm{~cm}$ and $40 \times 50 \mathrm{~cm})$, sealed, and allowed to float in water with ice (ice-water).

\section{Determination of the Torrymeter Readings}

The Torrymeter readings (TMR) were taken with a GR Torrymeter (GR International Electronics) just above the lateral line (skin side) and on the dorsal muscle (bone side) of the fillet. The meter was used in the individual mode.

\section{Determination of the $K$ Values}

Several slices of the dorsal muscle $(0.5-0.7 \mathrm{~g}$ each) were dissected from each fish, pooled, and mixed thoroughly. Five grams of the muscle was extracted with $10 \%(\mathrm{w} / \mathrm{v})$ perchloric acid (PCA) according to the method described by Nakajima et al. ${ }^{11}$ Contents ( $\mu \mathrm{mol} / \mathrm{g}$ wet muscle) of ATP and its degradation products in the PCA extract were estimated by the method of Kato et al. ${ }^{12)}$ The $\mathrm{K}$ value $(\mathrm{KV})$ was calculated by substituting these contents in the equation proposed by Saito et al. ${ }^{13)}$

\section{Results}

Torrymeter readings (TMR) and $\mathrm{K}$ values (KV) of fillets stored frozen and unfrozen are given in Table 1. The average value of TMR for fresh fillets (unfrozen) before storage was approximately 11 and that for the unfrozen samples held in ice for about a day were almost the same. Samples which had been frozen at $-20^{\circ} \mathrm{C}$ for about a day and subsequently thawed, in contrast, showed a value of 0 . This finding clearly indicates that TMR drop to extremely low levels with freezing which agrees well with the results reported hitherto. ${ }^{8)}$ It took about 18 days for the TMR of

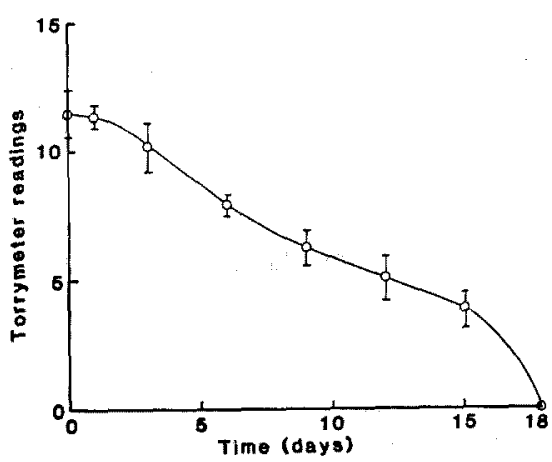

Fig. 1. Changes in Torrymeter readings of yellowtail fillets during ice storage.

Twelve fillets were used as samples before storage and 6 at a time for all other storage periods. Vertical bars represent standard deviations.

fillets kept in ice to reach 0 (more observation details are given in Fig. 1).

The average $\mathrm{KV}$ for fresh fillets before storage and for fillets held in ice for about a day were very low, i.e., less than $1 \%$ and approximately $6 \%$, respectively. The frozen samples gave a value between these two. Possibly, the KV of the frozen samples increased during thawing in ice-water. Fillets iced for 18 days showed a value of over $50 \%$.

Changes in TMR of fillets during ice storage are depicted in Fig. 1. The values decreased very slowly initially and fell rapidly later, resulting finally in 0 on the 18 th day.

Fig. 2 shows photographs taken of the skin and bone sides of the fillets stored frozen and thawed, and unfrozen. The skin of the fillets before storage was yellow in color along the lateral line. The bone side was reddish and bright on the surface (Fig. 2-A). After the samples were held in ice for about a day, the yellow line on the skin

Table 1. Torrymeter readings (TMR) and $\mathrm{K}$ values (KV) of frozen-thawed and unfrozen yellowtail fillets

\begin{tabular}{ccc}
\hline Fillet & TMR $^{* 3} \pm$ SD & KV (\%) \\
\hline Unfrozen (before storage) & $10.8 \pm 0.4$ & 0.3 \\
Unfrozen (stored in ice for $18 \mathrm{~h}$ ) & $11.2 \pm 0.4$ & 6.2 \\
Frozen (stored at $-20^{\circ} \mathrm{C}$ for $18 \mathrm{~h}$ ) & 0 & 2.6 \\
Unfrozen (stored in ice for 18 days) & 0 & 54.0 \\
\hline
\end{tabular}

$* 1$ Six fillets were stored at a time.

*2 The iced fillets were put in ice-water for $6 \mathrm{~h}$.

*3 The frozen fillets were thawed in ice-water for $6 \mathrm{~h}$.

*4 The iced fillets were submitted immediately to TMR measurement without being first placed in ice-water.

* Measured on skin side.

SD, standard deviation. 

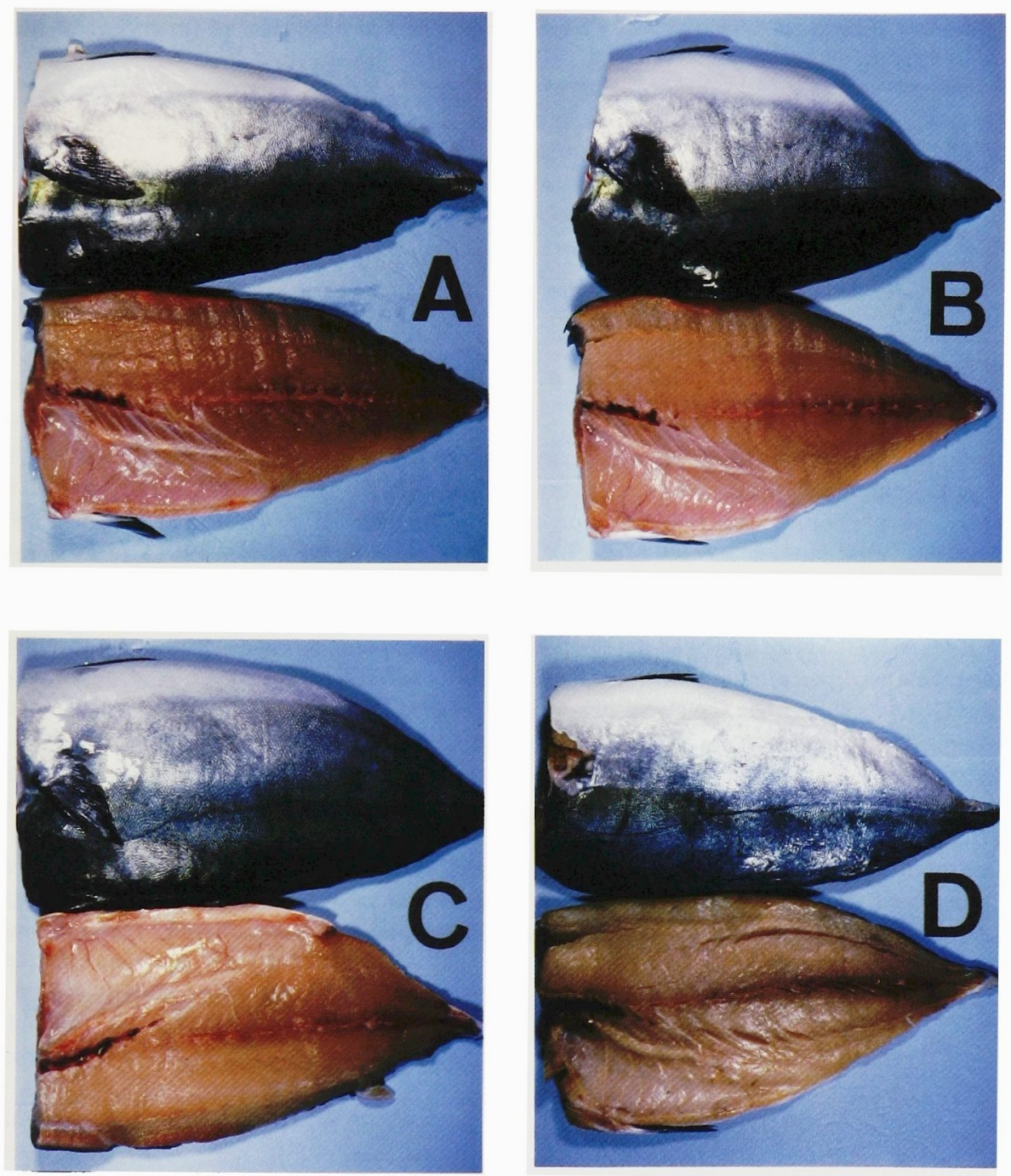

Fig. 2. Photographs of frozen-thawed and unfrozen yellowtail fillets.

A, fresh fillets before storage; B, unfrozen fillets held in ice for $18 \mathrm{~h}$ and put in ice-water for $6 \mathrm{~h} ; \mathrm{C}$, fillets frozen by storage at $-20^{\circ} \mathrm{C}$ for $18 \mathrm{~h}$ and thawed in ice-water for $6 \mathrm{~h} ; \mathrm{D}$, Unfrozen fillets held in ice for 18 days upper, skin side; lower, bone side.

remained largely. The muscle color did not change substantially but lost the brightness considerably (Fig. 2-B). The skin of all the frozen fillets, on the other hand, lost the yellow line completely. The muscle was almost the same in color and brightness as those observed for the fresh samples before storage (Fig. 2-C). The yellow line on the skin of the fillets iced for 18 days disappeared for the most part but a little still remained. The muscle turned pale brown and opaque on the surface (Fig. 2-D).
Since the skin color of the fillets had been changed by freezing at $-20^{\circ} \mathrm{C}$ for about a day, it was suspected that this slow rate freezing had caused the remarkable change. Therefore, we examined the change in TMR and the visual change in color of the surface of skin and bone sides of the fillets, upon freezing rapidly in liquid nitrogen and/or at $-20^{\circ} \mathrm{C}$. The results are shown in Table 2 and Fig. 3. Table 2 also includes TMR for unfrozen fillets taken on the bone side and again on the skin side for comparison. The TMR 
Table 2. Torrymeter readings (TMR) measured on skin and bone sides of frozen-thawed and unfrozen fillets

\begin{tabular}{|c|c|c|c|}
\hline Fillet*1 & Skin side & \multicolumn{2}{|c|}{ Bone side } \\
\hline Unfrozen (before storage) & $11.0(2)$ & 15.0 & (2) \\
\hline Unfrozen (stored in ice for $18 \mathrm{~h}$ ) $* 2$ & $11.5(2)$ & $12.5\rfloor$ & $(8)$ \\
\hline Frozen (stored at $-20^{\circ} \mathrm{C}$ for $18 \mathrm{~h}$ )*3 & $0 \quad(8)$ & $2.9=$ & $3(8)$ \\
\hline Unfrozen (stored in ice for 18 days)*4 & $0 \quad(6)$ & $1.3 \pm$ & (6) \\
\hline Frozen (dipped in liquid nitrogen) $* 5$ & $0 \quad$ (4) & 0 & (4) \\
\hline $\begin{array}{l}\text { Frozen (dipped in liquid nitrogen and stored } \\
\left.\text { at }-20^{\circ} \mathrm{C} \text { for } 18 \mathrm{~h}\right)^{* 5}\end{array}$ & $0 \quad(2)$ & 3.0 & (2) \\
\hline
\end{tabular}

*1 Number of fillets used for TMR measurement is given in parenthesis along the values for skin and bone sides.

*2-4 The same as mentioned in the footnotes of Table 1.

*5 The frozen fillets were thawed in ice-water for $6 \mathrm{~h}$

measured on the skin side were 0 for all the frozenthawed fillets and unfrozen ones iced for 18 days. The TMR taken on the bone side for samples dipped only in liquid nitrogen were 0 . The TMR for those held in ince for 18 days and other frozen fillets were very low in level (1-3 on the average). The TMR taken on the bone side of all the samples, except for the ones frozen in liquid nitrogen, were higher by 1-3 units than when they were obtained on the skin side. This evidence also suggests that fillets frozen in iquid nitrogen and thawed can be differentiated from the unfrozen by a combination of TMR and KV. Although the KV for the samples frozen in liquid nitrogen and/or those frozen subsequently at $-20^{\circ} \mathrm{C}$ was not determined in the present study, it appears that this freezing does not bring about the greater rise in $\mathrm{KV}$ than freezing at $-20^{\circ} \mathrm{C}$.

The yellow line of the skin for fillets frozen by dipping in liquid nitrogen faded to a large extent but could still be recognized (Fig. 3-A). The color and brightness of the muscle on the bone side were similar to those observed for the fresh fillets before storage except that some slight splits between myotomes were recognized. For fillets frozen in liquid nitrogen and then stored at $-20^{\circ} \mathrm{C}$, the typical yellow line faded much more than the line for those frozen only in liquid nitrogen (Fig. 3-B). The muscle color and brightness were almost the same as those observed for fillets directly transferred to the freezer at $-20^{\circ} \mathrm{C}$. The slight splits between myotomes were also present.
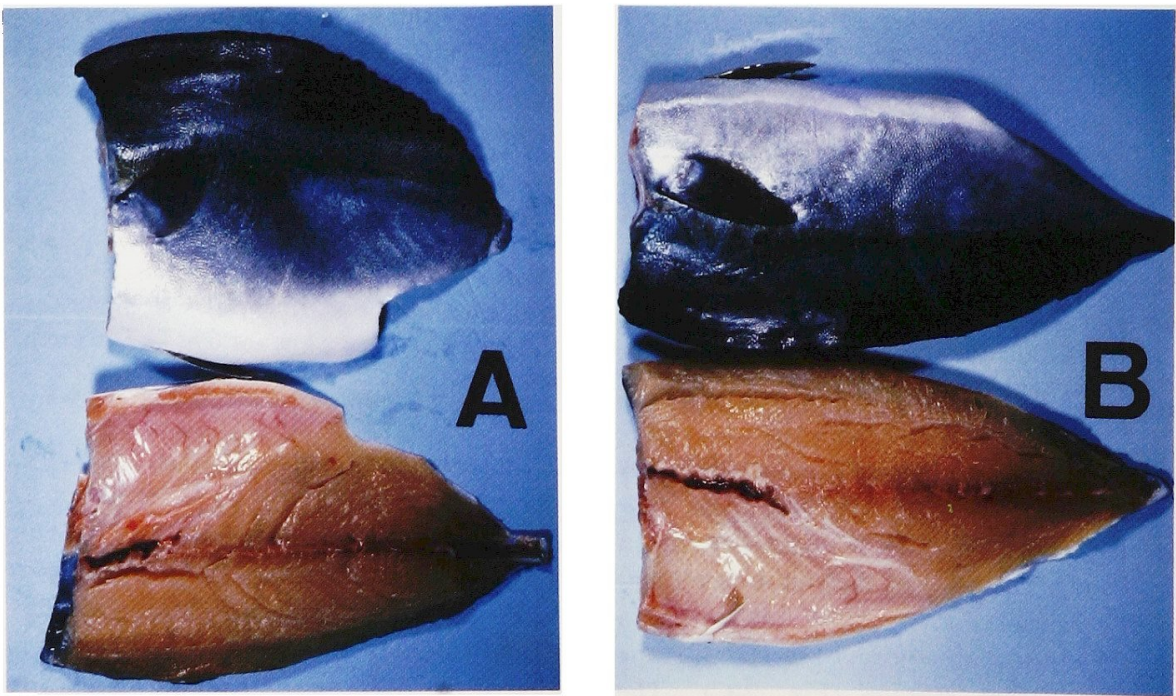

Fig. 3. Photographs of yellowtail fillets frozen in liquid nitrogen and stored at $-20^{\circ} \mathrm{C}$ for $6 \mathrm{~h}$ prior to thaw.

A, fillets dipped in liquid nitrogen for $45 \mathrm{~min}$ and thawed in ice-water for $6 \mathrm{~h}$; $\mathbf{B}$, fillets dipped in liquid nitrogen for $30 \mathrm{~min}$, stored at $-20^{\circ} \mathrm{C}$ for $18 \mathrm{~h}$, and thawed in ice-water for $6 \mathrm{~h}$; upper, skin side; lower, bone side. 


\section{Discussion}

The fillets before storage and those stored in ice for about a day had high TMR and very low KV (Table 1), suggesting that for given fillets to show such characteristics, they must be unfrozen and of high freshness. The filletts frozen rapidly in liquid nitrogen and/or in a freezer at $-20^{\circ} \mathrm{C}$ had extremely low TMR and also low KV (Table 1 and 2). It is this phenomenon that can be utilized to differentiate frozen-thawed from unfrozen fillets; when given fillets have these values, even though they are very fresh, they must have been frozen at least once in the history. Incidentally, "sashimi" of high quality is said to have $\mathrm{KV}$ less than $20 \%,{ }^{10}$ ) indicating that the shelf life of the yellowtail "sashimi" is approximately 6 days after the beginning of ice storage. ${ }^{14,15)}$ The TMR should thus be higher than about 8 (Fig. 1). The fillets stored for longer periods showed lower levels of TMR (Fig. 1), and the value reached 0 finally after 18 days (Table 1 and 2). Such fillets had KV over $50 \%$ (Table 1 ). When given fillets exhibit these lower TMR and higher $\mathrm{KV}$, their freshness should be low. It is difficult, however, to determine whether or not the fillets have once been frozen. In the later stage of ice storage, the fillets were unacceptable because of their rancid smell. ${ }^{17}$ ) Regardless of whether the fillets were measured on the bone or skin side, freezing by either liquid nitrogen or storage at $-20^{\circ} \mathrm{C}$ lowered the TMR markedly (Table 2). This indicates that the differentiation also can be made by using the TMR determined on the bone side. This finding, in turn, suggests that skinless fillets stored frozen and thawed can be differentiated from those stored unfrozen. In fact, Lees and Smith $^{10)}$ reported the similarity of TMR estimated on the skin side of skinless filetts and on the bone side of skin-on filetts. Additionally, the method for the differentiation presented here can also be applied to intact fish. In our preliminary investigation with carp, indicated that the TMR measured above the lateral line of intact fish was lower by 2 units than the level of fresh fish before storage; the fish were frozen for approximately a day at $-20^{\circ} \mathrm{C}$ and thawed in ice-water. No measurable difference was seen in the TMR for fresh fish and fish iced for the same period. The $\mathrm{KV}$ of the fish muscle before and after storage were similar to the respective values as found for the yellowtail fillets. Details of these results will be reported elsewhere. The procedures for differenting frozen-thawed fillets and the unfrozen, described in this report, had one difficulty. The determination of $\mathrm{KV}$ in the present investigation was carried out according to the conventional procedure, ${ }^{12)}$ which is rather time-consuming. Recently, however, some new methods have been developed to rapidly determine $\mathrm{KV}$ of fish muscle, e.g. using HPLC, ${ }^{18,10)}$ enzyme sensor, ${ }^{20)}$ test paper strip, ${ }^{20)}$ and oxygen electrode systems. ${ }^{21)}$ Therefore, this difficulty can be overcome by applying one of these methods.

Generaily, freezing is said to affect the dielectric properties of fish muscle tissues, consequently producing a decrease in TMR. ${ }^{9)}$ Most probably, the freezing of yellowtail fillets both in liquid nitrogen and at $-20^{\circ} \mathrm{C}$ changed remarkably the properties of the tissues. The TMR of fillets measured on the bone side were affected more by the freezing in liquid nitrogen than by the subsequent freezing at $-20^{\circ} \mathrm{C}$ (Table 2). This phenomenon seemed to result from the change in the muscle cell structure due to a higher temperature jump upon thawing; that is, the temperature difference of going from liquid nitrogen to icewater was larger than that from $-20^{\circ} \mathrm{C}$. On the skin side, the phenomenon was not observed, probably because of the difference in the tissue cell structure from that of the muscle.

The skin of the fillets lost the yellow line gradually during storage in ice, even though after 18 days they still retained the line a little. When the fresh fillets were frozen at $-20^{\circ} \mathrm{C}$, the line disappeared completely after about a day (Fig. 2), suggesting that this can also be utilized to distinguish frozen-thawed from unfrozen yellowtail fillets by a combination with either TMR or KV. When the fresh fillets were frozen rapidly in liquid nitrogen, the line was lost largely but remained slightly (Fig. 3). As the TMR measured on both the skin and bone sides were 0 for all samples (Table 2), the distinction could be made by measuring TMR together with KV. The bone side of frozen-thawed and unfrozen fillets, if both of them are kept fresh, was reddish and bright on the surface to a similar extent each other (Fig. 2 and 3). It was thus felt difficult to differentiate between frozen-thawed samples and the unfrozen by means of the visual observation.

\section{References}

1) S. Konagaya: Suisan-gaku Ser., 29, 93-112 (1979).

2) K. Yoshioka: Nippon Suisan Gakkaishi, 49, 149 
(1983).

3) K. Yoshioka: Nippon Suisan Gakkaishi, 51, 1331-1336 (1985).

4) H. Rehbein, G. Kress, and W. Schirelber: $J$. Sci. Food Agric., 29, 1076-1082 (1978).

5) H. Rehbein: Z, Lebensm. Unters. Forsch., 169 , 263-265 (1979).

6) V. Salfi, F. Fucetola, and G. Pannunzio: $J, S c i$. Food Agric., 36, 811-814 (1985).

7) K. Yoshioka and M. Kitamikado: Nippon Suisan Gakkaishi, 49, 151 (1983).

8) H. Uchiyama, S. Ehira, and N. Kato: Suisangaku Ser., 4, 81-103 (1974).

9) A. Cheyne: Fish. New Int., 14, 71-76 (1975).

10) A. Lees and G. L. Smith: in "Advances in Fish Science and Technology" (ed. by J. J. Connell), Fishing News Books Ltd., Surrey, England, 1980, pp. 300-403.

11) N. Nakajima, K. Ichikawa, M. Kamada, and E. Fujita: J. Agric. Chem. Soc. Japan., 35, 803-811 (1961).

12) N. Kato, H. Uchiyama, and F. Uda: Nippon
Suisan Gakkaishi, 39, 1039-1044 (1973).

13) T. Saito, K. Arai, and M. Matsuyoshi: Nippon Suisan Gakkaishi, 24, 749-750 (1959).

14) H. Uchiyama and S. Ehira: Bull. Tokai Reg. Fish. Res. Lab., 78, 23-31 (1974).

15) M. Murata and M. Sakaguchi: J. Food Sci., 51, 321-326 (1986).

16) H. Uchiyama, S. Ehira, H. Kobayashi, and W. Shimidu: Nippon Suisan Gakkaishi, 36, 177-187 (1970).

17) M. Sakaguchi, M. Murata, and A. Kawai: $J$. Food Sci., 47, 1662-1666 (1982).

18) M. Tsuchimoto, T. Misima, T. Utsugi, S. Kitajima, S. Yada, and M. Yasuda: Nippon Suisan Gakkaishi, 51, 1363-1369 (1985).

19) J. M. Ryder: J. Agric. Food Chem. 33, 678-680 (1985).

20) E. Watanabe and I. Karube: Suisan-gaku Ser., 60, 36-47 (1986).

21) M. Ohashi and Y. Utsugi: Suisan-gaku Ser., 60, 48-59 (1986). 